\title{
VIOLENCIA ARMADA Y GÉNERO: ANÁLISIS DE LA RELACIÓN A PARTIR DE LOS RELATOS DE VIDA DE JÓVENES MUJERES DE LA CIUDAD DE CÚCUTA Y SU ÁREA METROPOLITANA*
}

\section{ARMED VIOLENCE AND GENDER: ANALYSIS OF THIS RELATIONSHIP BASED ON THE LIFE STORIES OF YOUNG WOMEN FROM THE CITY OF CÚCUTA AND ITS METROPOLITAN AREA}

Nohora Constanza Niño-Vega**

\section{Resumen}

Objetivo. Se pretende reflexionar acerca de la relación de violencia armada y género a partir del análisis de los relatos de vida de jóvenes de la ciudad fronteriza de Cúcuta (Colombia). Metodología. Se realizaron entrevistas a profundidad con jóvenes habitantes de tres sectores marginales de la ciudad de Cúcuta y de su área metropolitana y tres relatos construidos con jóvenes mujeres infractoras de la ley. Resultados. Se plantea que la dinámica de la violencia armada que desarrolla el crimen organizado y la delincuencia común ha estado en transformación de su lógica armada y aunque existe involucramiento de jóvenes mujeres dentro de sus filas, aún se les incluye de manera diferencial en razón de su género. Conclusión. Las mujeres suelen compartir su rol como parejas, pues juegan un papel importante en la noción de mujer trofeo; asimismo, desarrollan el papel de pacificadores capaces y como objetos sexuales.

Palabras clave: género, violencia armada, jóvenes, sexualidad.

\begin{abstract}
Objective. The article aims to reflect on the relationship between armed violence and gender based on the analysis of the life stories of young people from the border city of Cúcuta (Colombia) and its metropolitan area. Methodology. In-depth interviews were conducted with young people from three marginal sectors of the city of Cúcuta and its metropolitan area, and three stories were built with young lawbreaking women. Results. It is argued that the dynamics of armed violence developed by organized crime and common crime, has been in transformation of its armed logics and, even though there is involvement of young women in their rank of crimes, they are still included differentially because of their gender. Conclusion. Women often play the role as couples since they play an important role in the notion of trophy women. Likewise, they also develop a role of capable pacemakers and sexual objects.
\end{abstract}

Key words: gender, armed violence, young women, sexuality.

\footnotetext{
* Este artículo surge como reflexión del trabajo de investigación doctoral "Las tramas de la violencia: construcción de subjetividad política en contextos de violencia armada” desarrollada entre el 2014 y 2017, por lo cual hace uso de los relatos construidos en dicho proceso.

** ITAM. Ciudad de México, México. E-mail: nohora.nino@flacso.edu.mx-

(D) orcid.org/0000-0002-6654-9536 Google Scholar
} 
Violencia armada y género: análisis de la relación a partir de los relatos de vida de jóvenes mujeres de la ciudad de Cúcuta...

\section{Introducción}

Colombia ha estado inmersa en un conflicto armado que ha sufrido modificaciones en las lógicas de guerra desarrollada por los distintos ejércitos enfrentados. La vinculación del narcotráfico a la guerra entre el Estado y las guerrillas, así como la aparición de los grupos paramilitares en el escenario bélico, su desmovilización y las recientes lógicas de reorganización en bandas de recomposición paramilitar o grupos pos-desmovilización, cambian la dinámica de una violencia política a la lógica de una violencia generalizada (Pécaut, 2001) en la cual estas distintas violencias se solapan.

El país no ha dejado de experimentar la violencia armada que se vive en las calles de los sectores urbanos particularmente marginados y, en el ámbito rural, donde las actividades como la siembra de cultivos de uso ilícito y sus rutas de salida, así como otro tipo de explotación de recursos -por ejemplo, la minería - se han convertido en las condiciones preponderantes para que los actores armados ilegales se posicionen en dichos territorios. Esta violencia se desarrolla bajo la lógica de las nuevas guerras (Segato, 2014), constituyéndose en formas de existencia en muchos de los lugares donde se desarrollan y en las que participan tanto actores estatales como privados.

En la ciudad fronteriza de Cúcuta y su área metropolitana, durante el ingreso paramilitar entre el período 1999-2004, se ejecutó una violencia indiscriminada, un dominio territorial por medio de la amenaza y el terror. Actualmente, los nuevos grupos que operan desarrollan un control territorial con procesos de intercambio en los lugares periféricos donde operan. Luego del paso del actor paramilitar en el país, arriban los grupos de recomposición paramilitar o bandas criminales que tomaron los territorios dejados por la desmovilización de los grupos paramilitares. Las Águilas Negras, Los Rastrojos y Los Urabeños -que transmutan en El Clan del Golfo y actualmente operan bajo el nombre de las Autodefensas Gaitanistas- se han apropiado de estos sectores debido a su riqueza en rutas de tráfico de drogas, pero también han ampliado sus actividades hacia otros negocios ilegales como el contrabando de gasolina, alimentos, mercancías provenientes de Venezuela y la extorsión a comerciantes y ganaderos.

En lo urbano, como lo señala el Instituto Nacional de Medicina Legal (2017), estos actores están estableciendo "actuaciones sincréticas entre delincuencia común y organizada, operando en el narcomenudeo de las sustancias psicoactivas en las instituciones educativas, lugares de diversión, hospedajes de bajo perfil y calles” (p. 106).

A lo largo de este conflicto y sus transformaciones, los actores armados visibilizados han sido históricamente masculinos ${ }^{1}$ y solo en los últimos años la mirada a la participación de la mujer

\footnotetext{
${ }^{1}$ No quiere decir con ello, enteramente conformado por hombres porque sería desconocer la participación de niños, niñas, jóvenes y mujeres dentro de estos colectivos armados, aunque como lo plantea Muñoz (2003) un porcentaje importante de los ejércitos sean conformados por hombres.
} 
en la guerra ha venido en crecimiento. A partir de esta perspectiva, nace una producción académica relacionada con dar voz a las mujeres que han sido víctimas del conflicto armado como madres, hijas, esposas, desplazadas, víctimas de violencia sexual o siendo usadas como botines de guerra.

Sin embargo, se ha transitado desde la mirada como víctimas hacia aquella que observa su participación dentro de los grupos armados (Lara, 2000; Blair y Londoño, 2003; Domínguez, 2003; Ibarra, 2009; Castro, 2011; Chamorro, 2012; Niño, 2016), y le reconoce el papel no solo desde el lugar de víctima -y con ello la idea del ser pacificador- sino también desde su rol activo militar como combatiente dentro de los grupos guerrilleros, particularmente del ELN (Ejército de Liberación Nacional) y de las FARC (Fuerzas Armadas Revolucionarias de Colombia), así como de los grupos paramilitares.

Es en el marco de esta perspectiva que este trabajo cobra sentido. Aportar en la mirada de la mujer joven como sujeto activo dentro de los grupos armados al margen de la ley, en este caso, los denominados grupos de recomposición paramilitar - Los Urabeños-, que se han convertido en actores que ejercen esta violencia difusa dentro de gran parte del territorio nacional, y que tienen una fuerte presencia en la ciudad fronteriza y su área metropolitana, dada su importancia como espacio estratégico para el narcotráfico y el control de otras actividades ilícitas.

Si bien los estudios desarrollados en el campo de la participación de la mujer en la violencia armada han presentado un importante conocimiento de su papel dentro de estos grupos, debido a que existe una creciente participación de los y las más jóvenes, se hace necesario comprender las dinámicas de su participación considerando que las formas en que se asumen las diferencias de género en la sociedad y que atraviesan también la vida de estos grupos pueden condicionar la manera en que estas jóvenes participan en ellos.

Con este fin, el documento toma como punto de partida el análisis de las relaciones de género que se desarrollan en estos grupos a partir de los relatos de jóvenes mujeres que han participado activamente, y de aquellas que viven en sectores donde estos actores ejercen su control. Es a partir de la experiencia narrada por quienes están al interior, y quienes están como observadores en espacios donde estos grupos actúan, que este documento explora algunas formas de ser y estar de las jóvenes mujeres dentro de ellos. En sus relatos, se evidencia una reproducción del estereotipo que se ha construido para las mujeres, en el que la idea de madre-esposas (Lagarde, 2005) define sus formas de incorporación y participación dentro de estos. Asimismo, la construcción de la mujer como un cuerpo para el goce, el intercambio y botín, como herramienta para ejercer el control social en los territorios donde operan estos grupos, ejes sobre los cuales gira la discusión de este documento. 
Violencia armada y género: análisis de la relación a partir de los relatos de vida de jóvenes mujeres de la ciudad de Cúcuta...

\section{Metodología}

El presente documento parte de los resultados de investigación doctoral en la que originalmente se desarrolló un trabajo etnográfico, así como grupos focales y entrevistas a profundidad con niños, niñas y jóvenes menores de 18 años. También se realizaron entrevistas a profundidad a tres jóvenes infractoras de la ley, que tuvieron participación en los grupos de recomposición paramilitar u operaron usando dichos nombres para cometer sus actos delictivos y quienes participaron de ellos siendo menores de 18 años, y entrevistas a organizaciones no gubernamentales y a informantes clave de la ciudad.

Los sectores donde se realizaron las entrevistas y grupos focales fueron elegidos por la incidencia de las tasas de homicidio para el año 2016 y la presencia histórica de una violencia generalizada. En la ciudad han operado milicias urbanas de los grupos guerrilleros ELN y las FARC, la presencia del Bloque Frontera de los paramilitares y actualmente la disputa de los grupos de recomposición paramilitar: El Clan del Golfo-Los Urabeños ${ }^{2}$ y Los Rastrojos.

Los nombres que aparecen en el presente texto son ficticios para guardar la confidencialidad y seguridad de los sujetos que participaron en los espacios de discusión y de las entrevistas.

El tratamiento de la información se desarrolló a partir de un análisis comprensivo de la categoría de género, haciendo énfasis en identificar los distintos roles que han desempeñado las jóvenes mujeres dentro de estos grupos y de qué manera estos roles acentúan las formas tradicionales de observar el papel de la mujer dentro del campo de la violencia armada. Se revelan elementos subjetivos que parten de una interpretación centrada en la experiencia narrada de los sujetos, con especial énfasis en las relaciones de oposición de género que profundizan, condicionan y diferencian la participación de las mujeres-jóvenes dentro de estos grupos.

\section{Discusión}

\section{La dinámica de la violencia armada en la ciudad fronteriza de Cúcuta y su área metropolitana}

La ciudad de Cúcuta ha vivido intensos períodos violentos que se mueven entre la violencia política en los años 80 y 90 con la presencia de milicias urbanas de las guerrillas del ELN, las FARC y el EPL (Ejército Popular de Liberación) quienes, de acuerdo con Cañizáres y Niño (2017), “aprovecharon esta región como una retaguardia de abastecimiento logístico, financiero y de atención médica a sus combatientes ”(p. 9), hacia la violencia de confrontación

\footnotetext{
${ }^{2}$ El grupo Los Urabeños ha sido nombrado de manera distinta en muy corto tiempo. Se autodenominan Autodefensas Gaitanistas de Colombia (AGC) y son nombrados por el Gobierno como El Clan del Golfo.
} 
aún en el campo político con la incursión del paramilitarismo ${ }^{3}$ entre los años 1999-2004 y, posteriormente, una violencia más difusa a partir de la desmovilización paramilitar del 2005 en adelante y la generación o recomposición de grupos pos-desmovilización vinculados a las actividades ilícitas.

Estos grupos, que en la región se han denominado Las Águilas Negras, Los Rastrojos, Los Urabeños, se han apropiado de estos sectores y se han extendido a territorio venezolano, disputándose zonas decisivas para las rutas de tráfico de drogas, pero también han ampliado sus actividades hacia otros negocios ilegales como el contrabando de gasolina, alimentos y otras mercancías provenientes de Venezuela y la extorsión a comerciantes y ganaderos (Cañizáres y Niño, 2017).

Hacia la comunidad, estos actores han mantenido algunas formas de actuación heredadas del paramilitarismo ${ }^{4}$ tales como el uso amenazante de panfletos que plantean “nuevas limpiezas” así como las restricciones de movilidad en horario nocturno, las restricciones a las jóvenes mujeres sobre su actuación y movilidad en sus entornos inmediatos a partir de amenazas que circulan a través de medios virtuales como la aplicación WhatsApp, enviando audios amenazantes a las jóvenes que se encuentren fuera de sus hogares a determinadas horas de la noche.

En estos territorios, los grupos mantienen su reclutamiento en las periferias donde los jóvenes pasan a formar parte de dichas bandas y sus redes de tráfico ilegal, bien a través del rapto de niños y jóvenes para ser entrenados dentro de los grupos, así como procesos de enrolamiento a partir del convencimiento y ofrecimiento del manejo de recursos económicos que resultan llamativos en una población donde la idea de movilidad social, a través de la educación y el trabajo, no se encuentra clara en su horizonte. Las autoridades policiales mencionan que, si bien el reclutamiento forzado anteriormente solía ser la herramienta de los grupos guerrilleros y paramilitares, ahora es el crimen organizado quien se encarga de dicho reclutamiento, procediendo a la iniciación temprana y progresiva a través del consumo y poco a poco a su vinculación en acciones delictivas.

\footnotetext{
${ }^{3}$ Aunque vale la pena señalar que las lecturas de las organizaciones defensoras de derechos humanos plantean que estas estrategias de contrainsurgencias estuvieron más al servicio de sus negocios y formas violentas de enriquecimiento y de control del poder público (INDEPAZ, 2017).

${ }^{4}$ Pero también mantienen diferencias tales como: una débil presencia de discurso político, la fragmentación en diferentes células y mandos sin estructuras jerárquicas como los anteriores grupos y un interés mayormente económico, que orientan sus actividades (Silvera, 2015).
} 
Violencia armada y género: análisis de la relación a partir de los relatos de vida de jóvenes mujeres de la ciudad de Cúcuta...

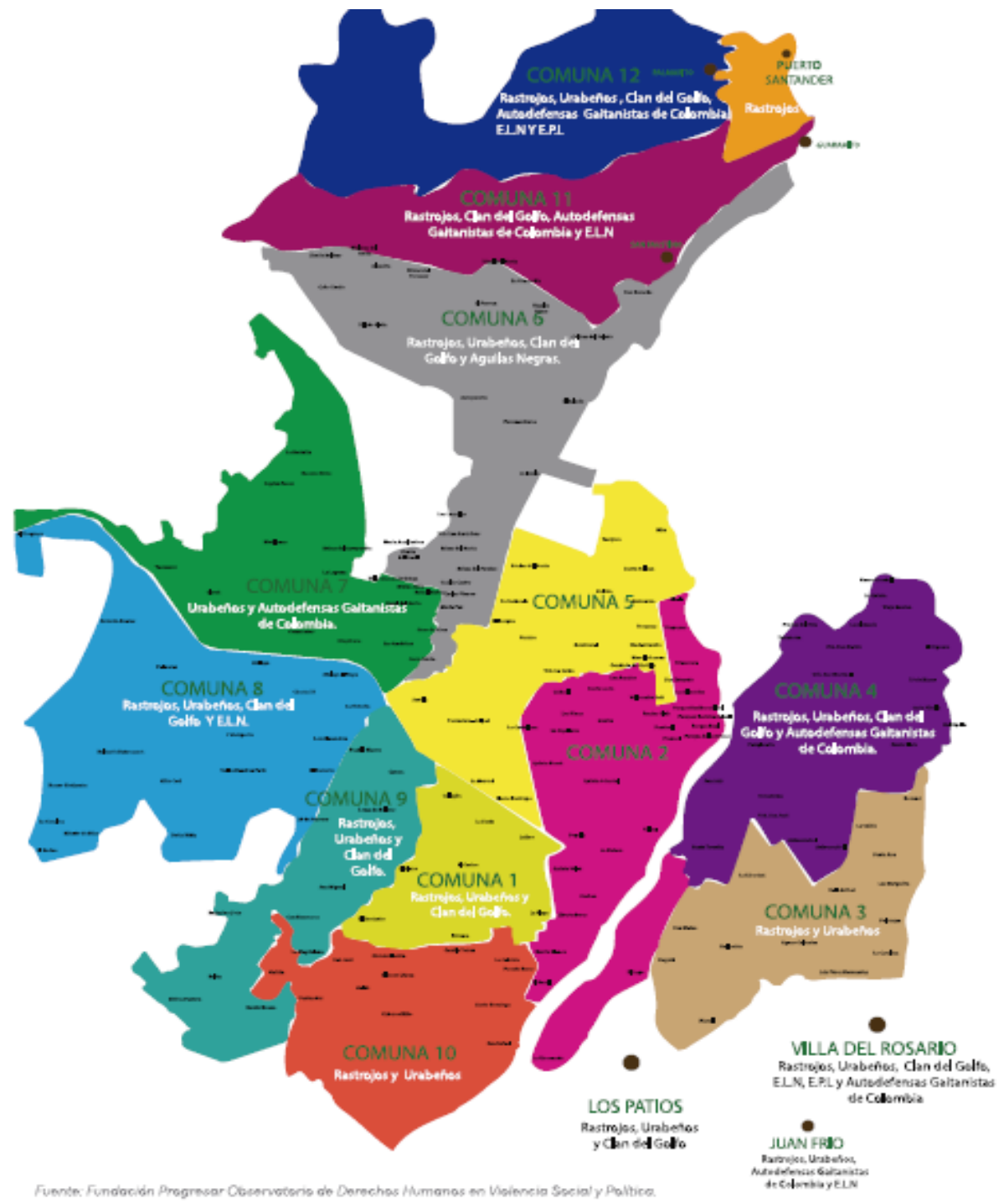

Fuente: Cañizáres y Niño (2017).

Figura 1. Mapa de actores armados ilegales en Cúcuta y su área metropolitana. 


\begin{abstract}
Allá por ese barrio, mientras yo subía a mi trabajo, uno ve que son muchos niños, pelaítos, que están trabajando para esos grupos, desde chiquiticos están ya metidos en eso, son muchos, ¡hum! como más de cien, eso se encargan de estar informando cuando sube la policía, de estar campaneando y llevando cosas. (Fernanda, comunicación personal, 16 de agosto de 2016)

Aquí dentro de la institución educativa sabemos que hay jóvenes que están siendo utilizados por actores de su barrio que manejan la droga y que buscan que ellos la introduzcan aquí y comiencen el negocio con los jóvenes y niños que están dentro de la escuela. (diálogo con informante en sector A, comunicación personal, 21 de febrero de 2016)
\end{abstract}

De tal manera que, la violencia reciente que vive la ciudad y su área metropolitana es compleja en su lectura, pero muy activa en las acciones armadas que se ejecutan y que mantienen el territorio en una situación de tensa calma. Es en el marco de este contexto de violencia dentro del cual las jóvenes se involucran.

\title{
Las mujeres jóvenes dentro de la violencia armada
}

La invisibilización del papel de la mujer dentro de la vida armada se ha enmarcado en la imagen de la mujer presentada como no violenta, dócil y pasiva ha potenciado esta mirada invisible de su participación en acciones de defensa y de protección (Blair y Londoño, 2003; Ibarra, 2009; Rayas, 2009).

No obstante, según González, González y Moscoso (2012) en los últimos años se presenta una mayor participación de las mujeres en acciones delincuenciales en Colombia, registrando aumentos de dicha participación en algunas ciudades como Bogotá, Medellín, Cali y Cúcuta entre los años 2008-2009. Dentro del estudio llevado a cabo en los centros penitenciarios lograron identificar que el 57\% de las mujeres recluidas están entre los 21 y 35 años de edad, que han iniciado sus carreras delictivas a muy temprana edad y provienen de los estratos 1 y 2 , con baja escolaridad, y el $84 \%$ se desempeñaba como jefa de hogar.

Como lo reporta su informe, entre los años 2009-2010, del 10\% de las mujeres capturadas a nivel nacional, el 32,54\% participó en tráfico, fabricación o porte de estupefacientes, seguido de un $30,52 \%$ por hurtos, el 4,13\% por tráfico, fabricación o porte de armas y solo un 1,25\% en homicidios, porcentajes que nos dan una muestra de las funciones que suelen ocupar en el espacio del mundo de la criminalidad. 
Violencia armada y género: análisis de la relación a partir de los relatos de vida de jóvenes mujeres de la ciudad de Cúcuta...

\section{Gráfico 1. Investigaciones iniciadas por el delito de tráfico, fabricación y porte de estupefacientes 2007-2016}

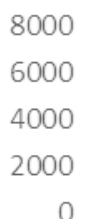

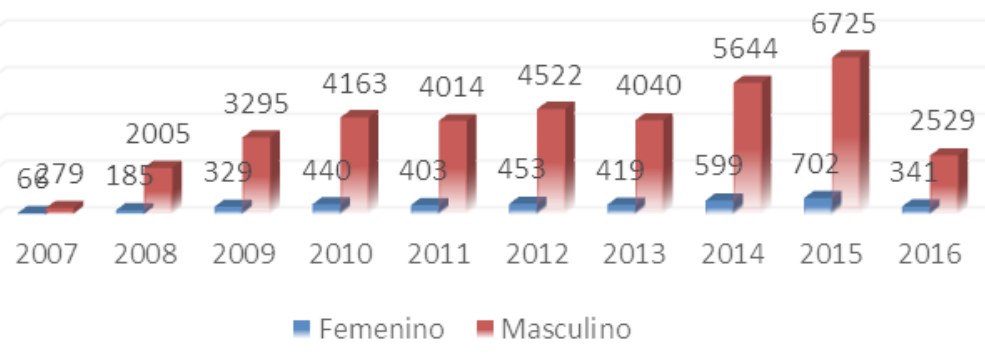

Fuente: elaboración propia con datos de la Dirección Nacional de Seccionales y de Seguridad Ciudadana, Fiscalía General de la Nación, Colombia. La fecha de corte de la información ha sido el primer semestre del 2016.

En materia de edad, se observa que en la última década un total de 3.937 niñas y jóvenes menores de 18 años han participado en la comisión del delito de tráfico, fabricación y porte de estupefacientes dentro de las cuales el 21,57\% reporta contar con estudios de secundaria, el 20,92\% primaria y de un 56\% no se tiene información sobre su grado de escolaridad. Pese a que al comparar en materia de género el número es significativamente menor respecto a la participación de niños y jóvenes en la comisión de este delito, lo que resulta importante mencionar es que el comportamiento de las cifras a lo largo de la década muestra un paulatino aumento de la participación de las niñas y jóvenes dentro del mundo de la ilegalidad. Aunque la cifra de participación por edades no viene discriminada por género en la información recabada, el comportamiento general muestra que las edades de mayor involucramiento son de los 14 a los 17 años.

Es el caso de las jóvenes que ingresaron al mundo de la actividad ilegal, quienes participaron siendo menores de 18 años en los actos delictivos por los cuales se encuentran en el programa como infractores de la ley, particularmente por participar del delito de extorsión, dos de ellas, participantes del grupo Los Urabeños y una, quien junto con su pareja decidieron extorsionar por su cuenta haciendo uso del nombre de este grupo.

Yo estoy aquí porque cometí un delito de menor (...) Me da pena hablar del delito... ahora soy diferente, mi delito fue extorsión, tiene más cosas, pero obviamente los agravantes no, porque no tenían pruebas. (Marcela, comunicación personal, 26 de abril de 2016) 
Yo también cometí el delito de la extorsión, lo único diferente aquí es que para eso no es necesario usar armas porque si usted llega diciendo yo soy de tal cosa, entonces la persona se achanta, usted pide y él se lo va a dar, en cambio al robar es posible agredir o matar a la persona por quitarle las pertenencias. Lo que nosotras hacíamos no hería a la persona, pero uno sí la agredía verbalmente y le hacía daño psicológico. ${ }^{5}$ (Jimena, comunicación personal, 26 de abril de 2016)

Como lo expresa Lagarde (2005), existen diferencias genéricas en torno al delito que se evidencia en la participación significativamente menor de las mujeres dado que su modo de vida doméstico, privado, sus funciones y sus relaciones vitales parecen hacer infrecuente la delincuencia. La transgresión a las normas, señala la autora, confiere valor genérico, éxito, prestigio y rango. La virilidad, el grado de machismo, se mide en parte por la capacidad de transgresión frente a la norma, de tomar objetos de otros y de vencer el miedo a la prohibición, a la sanción y al castigo, con lo cual se puede comprender esta diferencia importante entre la participación de los hombres frente a las mujeres en las actividades delictivas.

Pero, adicionalmente a la generización de la participación en la violencia armada como una construcción simbólica de poder y estatus que ayuda a fortalecer el rol masculino, es cierto también que las organizaciones ilegales han aprendido a jugar con las formas en que las relaciones sociales se han generizado y los modos en que se perciben a unos y otras. La incorporación de las mujeres en este mundo armado también se ha promocionado en la medida en que bajo su mirada de sujeto no transgresor de las normas podía facilitar su movimiento frente a las autoridades por no ser un sujeto de sospecha, además de sus labores de inteligencia a partir de ofrecerse como un objeto del deseo. De igual manera, el uso y vinculación de niños, niñas y jóvenes menores de 18 años se ha desarrollado en ese sentido, por un lado, la idea de lo infantil como un sujeto inocente y, por otro lado, las facilidades jurídicas en materia de su procesamiento penal por participar de estas actividades delictivas.

No obstante, la literatura académica referida a su participación dentro de los grupos criminales menciona que la posición de estas sigue estando al margen de los mandos de poder y desarrollan al interior actividades más pasivas (Lagarde, 2005; Ovalle y Giacomello, 2008; González et al., 2012; Comisión Interamericana de Mujeres, 2014; Castelletti, 2016). Poco a poco han asumido distintas funciones, aunque por lo general su participación se encuentra en el nivel más bajo, como portadoras humanas y microtraficantes a nivel local con un rol importante en el traslado y venta al menudeo de drogas (Castelletti, 2016).

\footnotetext{
${ }^{5}$ Es importante mencionar que en el momento en que se les realizó la entrevista ellas ya llevaban cumpliendo un año de asistir al programa. No se encuentran encarceladas, deben cumplir con un calendario de asistencia al programa de atención y reinserción donde realizan distintas reflexiones sobre los delitos cometidos. Por tal razón, esta parte del relato de Jimena se comprende en el marco de las reflexiones que allí han realizado.
} 
Violencia armada y género: análisis de la relación a partir de los relatos de vida de jóvenes mujeres de la ciudad de Cúcuta...

A continuación consideraremos, de acuerdo a los relatos, el doble papel como parejas que pueden participar y apoyar las acciones de los hombres al mando, también como pacificadoras y conversoras a una vida legal y, por último, su cuerpo como intercambio, como objeto del deseo y el goce.

\title{
Su involucramiento como parejas en el mundo de la ilegalidad
}

En el caso de los delitos que cometen, en las bandas de narcotráfico hay una que otra mujer y generalmente funcionan "acompañadas de sus parejas o familiares que las protegen y las usan" (Lagarde, 2005, p. 654). En algunos casos, las mujeres no son reconocidas como parte de la banda sino como ayuda a la misma. Para Ovalle y Giacomello (2008), las mujeres son vistas en el mundo del narcotráfico como "narco madres, narco esposas, y narco hijas" que evidencian las relaciones patriarcales estructuradas dentro de este mundo ilegal.

\begin{abstract}
La percepción con las adolescentes es que se inician o se vinculan a través de su pareja, con el chico, su pareja directa, su novio que ya está involucrado en el microtráfico y que ella queda conectada a partir de ser su novia, esto es lo que se ha podido percibir de lo que sucede en las regiones. La novia es la que porta la droga, la que sirve de bolso, de maletín, ella es la que siempre carga la droga y el hombre la promueve y la comercializa. (Informante clave 1, comunicación personal, $13 \mathrm{de}$ abril de 2016)
\end{abstract}

Marcela, una joven de 19 años que vive en la ciudad de Cúcuta, nos narra cómo desde los 12 años decide salirse de su casa y vivir en el país vecino con un hombre mayor. A partir de este nuevo escenario fuera de su familia, habla de sus comienzos en el consumo de sustancias psicoactivas y su involucramiento en el mundo de las acciones ilegales. A la edad de los 14 años conoce a un joven que en sus palabras:

era el hijo del cacique, así les llaman a los duros allá... Yo quería todo, yo quería el premio mayor, el hijo de un duro o un duro, sí, esa es la verdad. (Marcela, comunicación personal, 26 de abril de 2016)

Su experiencia de vínculo con el grupo inicia a partir de un elemento que muestra la distinción y el poder dentro de este mundo. Este se refiere a la idea de mujer trofeo (Valenzuela, 2010) que opera como un elemento de prestigio para quien la detenta, que tiene la capacidad de mostrar su poderío, jerarquía y distinción de los otros con los que comparten ese mundo. A su vez, esa dinámica le permite a Marcela hacer uso de su cuerpo como táctica para acceder a una posición que no tendrá fácilmente de otra manera. Sabe que los jefes escogen entre las jóvenes y mujeres más bellas y este tipo de elección le da a ella este estatus. Mientras él la elige como su mujer trofeo, ella también ingresa a dicho juego porque sabe que a través de él viene el reconocimiento y el respeto de los otros, los cuidados y la protección. 
Marcela relata la historia de un joven que fue asesinado por estarla cortejando, y dicho asesinato lo adjudica a la necesidad del hombre de "hacer sentir el nombre", evidenciar el poder que tiene y la capacidad de decidir sobre la vida de los otros pares masculinos, así como la vida de las mujeres que les acompañan en tanto reconoce que ellas pasan a ser de su propiedad: "Ellos creen que uno es de su propiedad, que son dueños y señores de todo" (Marcela, comunicación personal, 26 de abril de 2016). En este sentido, la violencia armada también se estructura como acción simbólica a partir del cuerpo femenino. Una acción que juega como reconocimiento, prestigio, poder económico con el fin de marcar el territorio del y por el cuerpo.

Estos vínculos también generan un reconocimiento fuera del círculo del mundo armado ilegal. Hacia la sociedad más próxima hay un dominio sobre los otros que se genera por mantener esta relación con un sujeto que genera temor dentro del espacio donde opera:
(...) un ejemplo, entre usted y yo hace muchos años, usted me tenía respeto a mí porque yo era familia o novia de un duro, ahorita en estos momentos pues yo ya no soy nadie. Pues ya no voy a decir voy a matar a este porque no me cae bien, pues ya no. (Marcela, comunicación personal, 26 de abril de 2016)

Esta dinámica se desarrolla de forma similar a otros niveles en el mundo de los grupos ilegales. En entrevistas realizadas con jóvenes mujeres de 15 años de un sector de la ciudad, expresan que los jóvenes involucrados dentro de los grupos de delincuencia que mantienen el control en dichos sectores, también eligen a las mujeres en una relación de sujeción como mujeres trofeos con las cuales hacen evidente su estatus. Estar involucrada con un "duro del barrio" les permite darse un lugar de reconocimiento en dicho espacio, en especial frente a sus pares mujeres.

En este sentido, como lo expresa Segato (2014), en el cuerpo de las mujeres se realiza una escritura "como documento de la efímera victoria" (p. 23), el cuerpo se revela como una herramienta que posibilita, ante la ausencia de otros medios, usarlo como insignia de quien detenta la autoridad. Por eso, también los cuerpos son jerarquizados y categorizados bajo el binomio belleza/fealdad, que les permite construir esta distinción de posición y autoridad, de manera que la propiedad sobre el cuerpo bello de la mujer es un recurso material y simbólico para plantar su estatus dentro del grupo.

Ahora bien, en su experiencia particular, Marcela también llegó a manejar las cuentas y el dinero del negocio, y cuando su pareja es capturada ella manifiesta que tuvo en sus manos todo el negocio y al mando la gente que trabajaba para él. Pero Marcela duda de sus capacidades y de la posibilidad de seguir con él por su cuenta y no es sino hasta que su "hermano de calle" le propone llevar el negocio juntos, que ella decide asumirlo. De tal manera que, pese a que ella misma narra en su relato que llevaba el control del negocio, no siente que tiene el poder a menos que sea acompañada de una figura masculina que pueda ejercerlo ante los otros: 
Violencia armada y género: análisis de la relación a partir de los relatos de vida de jóvenes mujeres de la ciudad de Cúcuta...

\begin{abstract}
(...) no sabía qué iba a hacer, porque yo todo lo hacía con él y con mi hermano [de la calle], hacía negocios con él, sola, no, de pronto había sacado el negocio porque uno es coco [inteligente] para eso, tengo algo que la gente dice que soy enredadora, pero no sabía qué hacer, esa gente no me va a hacer caso, pensaba yo, tenía mucha gente al mando, sí, mucha, pensaba que no iba a ser capaz, era muy terrible porque yo si me puse derecho con todo, claro, que yo me metí mucho en esa vida, la droga, los paracos, cuentas, cobros. (Marcela, comunicación personal, 26 de abril de 2016)
\end{abstract}

Marcela tiene el conocimiento que le permite manejar y controlar el negocio que ha dejado su pareja al ser arrestado, pero se siente intimidada por asumir un papel que ha sido eminentemente masculino en un mundo violento en el que esta figura es hegemónica. Es en situaciones como estas donde precisamente el género como dispositivo regulador de la vida social y de las experiencias particulares de las mujeres y jóvenes se pone de manifiesto.

En este contexto, las mujeres no son vistas como sujetos con capacidad para liderar acciones y, por tal razón, la dificultad para asumir un papel que está allí disponible. Esta es una realidad sexuada que se ha ido integrando en su construcción subjetiva y su experiencia de vida. En este sentido, ella difícilmente se imagina asumiendo sola dicha posición, sin querer decir con ello que no le llamara la atención, por el contrario, le resultaba llamativo poder dirigir el negocio ante el vacío generado por su pareja, pero se contuvo hasta que la figura masculina aparece.Y no solo por una falta de agencia para promover su liderazgo, sino también porque el contexto de violencia armada de la ciudad mantiene una dinámica masculina hegemónica en su interior que incluye y excluye a la mujer de determinados espacios, uno de ellos, el de liderazgo, que hace que dicho espacio resulte más complejo si es ella quien encabeza el grupo, dado que la feminidad es concebida allí como sinónimo de debilidad y subalternidad

Ahora bien, en el caso de los cortejos realizados por el "dueño del barrio" a las jóvenes de sectores marginados de la ciudad, también se evidencia este tipo de relación de poder que emana por los vínculos. Mientras María, de 14 años, manifestaba que había sido cortejada por el duro del barrio, una compañera del barrio y del colegio, Martha, de 15 años, con quien mantenía relaciones cercanas, pero también tensionantes, le manifestaba que él no tenía tanto poder como decía tener, que realmente era de los que se creía con influencias, pero no era así.

De tal modo que, para disminuirla en su reconocimiento e importancia, Martha apela a desacreditar el poder que realmente podía tener quien la cortejaba. No valía la experiencia de

\footnotetext{
${ }^{6}$ Se trata de una figura que suelen referenciar las y los jóvenes dentro de los grupos focales y las entrevistas para señalar a la figura masculina que controla el negocio y la vida delictiva dentro de este espacio.
} 
María en la calle, como parte del "aguante femenino” de La banda del Indio ${ }^{7}$, su estatus puede cambiar por el hecho de las relaciones que pueda establecer con alguien, a menudo hombre, que detenta el poder dentro de este escenario. En la experiencia de María, el poder y estatus de quien la corteja es puesto en duda y, a través de éste, también su propio reconocimiento.

La experiencia social de cómo se construye el género y las caracterizaciones que definen el ser mujer, terminan por condicionar las capacidades de estas dentro este espacio que ha sido definido eminentemente masculino y donde ellas revisten un papel secundario en términos de control, pero fundamental para la ratificación del poder del hombre hacia los otros.

\title{
Las jóvenes vistas como cuerpos de intercambio y sujetos de repulsión
}

Las vidas de los sectores marginados comparten la presencia de los actores armados que se dedican al negocio del microtráfico de sustancias psicoactivas. En estos espacios, jóvenes en grupo se reúnen en las esquinas para "parchar", en muchos casos tomando los pocos espacios de recreación de dichos barrios para su propio esparcimiento.

Dentro de estos parches - grupos de jóvenes con los cuales comparten intereses-, María y Martha comentan haber estado compartiendo y dialogando y, aunque ellas manifiestan sentirse como pares dentro de estos espacios, lo cierto es que, en algunos casos, tanto desde sus propios compañeros hombres como desde su familia y vecinos, suele vérseles como jóvenes con una vida sexual activa y promiscua, razón por la que terminan siendo juzgadas bajo los criterios morales de lo que significa una "mujer de bien".

En el caso de María, una de las preocupaciones fundamentales de su madre no es solo si participa y consume sustancias psicoactivas sino, particularmente, si ha tenido relaciones sexuales a temprana edad. Ella se ha sentido juzgada por su familia y sus vecinos, quienes la han visto como una joven de la vida fácil, sobre la cual se mantiene un fuerte juicio respecto al deber ser del sujeto femenino, resguardado y ajeno a la exposición pública de su vida sexual.

\begin{abstract}
A mí me decían "Mita [mamita] déjese tocar y yo le doy esta bolsita" y yo le decía "No pito [papito], yo no necesito venderme" así toda trabada, no necesito venderme papito, pa' eso le digo a un chino que me preste, o pa' eso le digo a alguien que me regale un poquito, yo por venderme por eso, papi está perdido, yo no estoy como esas chinas que se venden por eso, no papi abra paso, toda trabada yo le decía así, porque sabía todo eso, no, no, a mí no me venga con esos cuentos, los chinos me decían, vamos y me acompañan, vaya y que los acompañe su
\end{abstract}

\footnotetext{
${ }^{7}$ Barra brava seguidora del equipo de fútbol Cúcuta Deportivo, que ha tenido estigmatizaciones durante mucho tiempo por habérsele involucrado en el mundo del consumo de drogas en la ciudad.
} 
Violencia armada y género: análisis de la relación a partir de los relatos de vida de jóvenes mujeres de la ciudad de Cúcuta...

madre pirobos y los sacaba a perder. (María, comunicación personal, 11 de mayo de 2016)

Aquí el cuerpo femenino tiene un papel fundamental ligado a la dinámica de intercambio sexual que se efectúa para acceder a beneficios y espacios dentro de este mundo. Su cuerpo abre la posibilidad al goce y disfrute de los hombres, y este elemento les posibilita el valor de cambio con el cual ellas pueden maniobrar y realizar transacciones que les resultan fundamentales para su existencia, no solo por el acceso al consumo, sino también dentro de su labor activa en los grupos ilegales.

Bajo esta idea del uso del cuerpo como goce, ellas son preparadas para el ejercicio de la extorsión, la conquista, el coqueteo, y con ello la acción criminal las alienta a enfatizar precisamente en esta lógica relacional. El cuerpo es su arma para cometer delitos. Mientras el hombre dentro del grupo cuenta con el arma para accionar y coaccionar, en las mujeres es su sexualidad, deben estar en disposición de usarla antes que cualquier otra herramienta.

El relato de María enfatiza el hecho de que las jóvenes que participan de estos parches suelen ser tratadas por sus pares hombres como objetos del deseo sexual, buscan que ellas intercambien su cuerpo por la droga que circula en dicho espacio, y ella también juzga a sus pares mujeres que han participado de este mundo y que han accedido a estos intercambios.

Para Pedro, un joven de 14 años que a su corta edad ha participado de estos parches y de otras dinámicas de grupos armados en el sector, las jóvenes que se encuentran socializando con ellos dentro de estos grupos reciben un reconocimiento como mujeres leales y fuertes porque se encuentran en un espacio que ha sido históricamente catalogado como masculino, donde el arrojo, la valentía y la fuerza son cualidades que se requieren para permanecer allí. No obstante, también son sometidas a juicios por ellos, que las desdeñan como posibles parejas afectivas debido a que su exposición sexual abierta con ellos no las hace merecedoras de dicha posición. Los sentimientos que generan estas jóvenes mujeres son de repulsión:

En una mujer eso se ve feo.

¿Qué se ve feo?

Que sea drogadicta, porque yo conocía a unas que también, una chama [mujer joven] abajo que se llama Puchis, ella también es pegantera, uno al principio lo ve bien, que se ve como locata, pero después con el tiempo ya da es como asco, ya comienzan a vestirse y a andar (...) ya a uno le da como cosa arrimárseles y se vuelven también tremendas, ya después de la droga hacen muchas cosas.

¿Qué tipo de cosas?

Se comienzan a acostar con todas las personas. (Pedro, comunicación personal, 05 de mayo de 2016) 
En este nivel, a las jóvenes mujeres que participan de la vida de la ilegalidad como consumidoras, se les asume como sujetos de inferioridad y de desprecio debido al uso que le dan a su cuerpo como valor de intercambio para mantener su consumo. Si la mirada del consumidor ha sido de lástima y desprecio al considerarlos no sujetos precisamente por observarse como personas desposeídas de sí a través del consumo de la droga, las jóvenes se encuentran en un doble proceso de desposesión: en un primer momento deben intercambiar su cuerpo para favorecer su consumo y, en un segundo momento, ese mismo cuerpo es desposeído debido al consumo que le impide tener un dominio de sí. De tal manera que las jóvenes que atraviesan por el consumo, son sujetos del desprecio y la repulsión tanto de la comunidad y su familia como de sus pares consumidores (Niño, 2017).

Por otro lado, en el nivel de la vinculación a grupos como Los Urabeños y Los Rastrojos, se ha tenido conocimiento de que estos actores se encuentran ejerciendo reclutamiento forzado de jóvenes menores de 17 años con fines de explotación sexual.

\begin{abstract}
Hemos tenido conocimiento que estos grupos están seduciendo, a partir de la idea de un trabajo bien remunerado, a jóvenes para que vayan a los campos a trabajar. En la zona rural de la ciudad de Cúcuta le ofrecieron trabajo a una joven, al principio la llevaron a una finca y allí estaba desarrollando labores de cocina, cocinándoles a obreros y, posteriormente, se la llevaron a otra finca donde tenían más o menos a 50 jóvenes en entrenamiento militar. Allí su labor cambió, ella fue presionada para acceder a tener relaciones sexuales con los jóvenes, la explotaron sexualmente y, junto con ella, más o menos 10 jóvenes más. Por supuesto, estas actividades deben realizarlas bajo la amenaza contra su vida y la de sus familiares. (Informante 2, comunicación personal, 31 de marzo de 2018)
\end{abstract}

La explotación sexual de las jóvenes mujeres se convierte en la herramienta que estos grupos armados utilizan para generar un apoyo moral a partir del entretenimiento sexual de los más recientes miembros de los grupos, jóvenes que han sido reclutados y se encuentran en la iniciación de la vida armada. Esta explotación sexual, además de servir como actividad "recreativa", sobre todo tiene una profunda connotación a nivel de que se ha denominado la pedagogía de la crueldad, es decir, en el aprendizaje de cómo dicha violencia contra el cuerpo de la mujer es una "rapiña que se desata sobre lo femenino tanto en formas de destrucción corporal como en las formas de trata y de comercialización de lo que estos cuerpos pueden ofrecer, hasta el último límite” (Segato, 2014, p. 17). Los jóvenes aprenden a través de dichas prácticas sobre la depredación de estos cuerpos y las posibilidades que esta brinda en el control y dominio de las poblaciones de los territorios que son de su interés, por tanto, se compone en una estrategia militar central. En este sentido, como lo señala la autora, este tipo de agresiones que se desarrollan por medio de lo sexual tienen un sentido que va más allá de este orden: el 
Violencia armada y género: análisis de la relación a partir de los relatos de vida de jóvenes mujeres de la ciudad de Cúcuta...

poder. No es el goce y la satisfacción su fin último, es la expresividad de la violencia ante un público mudo. A partir de esta violencia, se enfatiza en la construcción de la mujer como un sujeto dominado y disciplinado.

El cuerpo femenino entonces se convierte en el texto sobre el cual los nuevos militantes de los grupos armados ilegales tienen la posibilidad de aprender la crueldad con la cual deben maniobrar para ejercer su rol como sujetos armados. Placer, consumo y dominio, son parte de la relación que estos nuevos militantes aprenden en el acceso al cuerpo de estas mujeres jóvenes.

\section{Su lugar como pacificadoras y redentoras de la "mala vida"}

Si hay un lugar que les ha sido asignado a las mujeres dentro de la historia de la guerra, este ha sido el de la figura del diálogo y la negociación. Rayas (2009) identifica algunos elementos que dan cuenta del por qué del discurso que las excluye de su papel como guerreras en los espacios de violencia armada. Por un lado, se encuentra la maternidad, que influye desde tres lugares relacionados entre sí: la función reproductora, como dadora de vida que se concibe como contrasentido del combatiente que quita la vida y, por último, su relación con la idea de pacifismo, dado su carácter de cuidadoras de vidas que las lleva a tomar partido por la paz. Vistas en términos de población civil se asumen como los sujetos por los cuales se pelea, a los que se protege y, además, las que como retaguardia pueden ayudar a cumplir funciones de cuidado de las familias y las propiedades. Como trofeos de guerra, que se traduce en el uso de la violencia como arma de guerra. Asimismo, también se le tiende a adjudicar una carencia de atributos bélicos, dado que no se correspondería de acuerdo a la construcción de lo femenino, con los valores propios del campo armado, fuerza física, heroísmo, arrojo, estrategia (Rayas, 2009).

En este sentido, dentro de los grupos ilegales también se han creado estas representaciones del sujeto femenino, que las ponen en el lugar de lo que Lagarde (2005) menciona como las madre-esposas, una figura que relaciona la maternidad y la conyugalidad que las define como un ser para y de otros, es decir, un rol de cuidado al cual los sujetos del mundo ilegal le otorgan un sentido de conversión. A las jóvenes mujeres que se establecen como parejas, les son atribuidas las características maternales y de conyugalidad relacionados con la capacidad de conversión, dado que estas relaciones también implican asumir responsabilidades de protección, seguridad y estabilidad que se supone el sujeto masculino debe proveer mientras que el sujeto femenino busca apaciguar, cuidar y alimentar.

Dentro del relato de María, ella refiere que "el duro del barrio" le plantea la idea de conformar una pareja y con ello su compromiso a abandonar la vida que lleva al interior: 
(...) sí ve, vea yo la quiero a usted como mi mujer, y yo me eche a reír, por qué se ríe si eso es normal, dijo, la única muchacha del barrio que me ha parecido bien bonita es usted, que es bien alegre, que da ejemplo, que me dice a mí que cambie, él me dice a mí, yo cambio si usted es mi mujer, o sea, él entrega todo eso, la pistola, la entrega por mí y él se pone a trabajar, él está trabajando, pero él entrega la pistola y todo eso. (María, comunicación personal, 11 de mayo de 2016)

Las asignaciones culturales de género que han construido a la mujer como una persona dulce, tierna, hospitalaria y amistosa, terminan configurando la idea de un sujeto de paz que tiene la capacidad, pero además la responsabilidad, de realizar un proceso de resocialización a sus parejas participantes de la actividad ilegal, se enfatiza en la idea mariana de la moralidad y la espiritualidad.

En este sentido, la figura femenina es observada como el bálsamo y refugio que permite salir y descansar de una vida abrumadoramente violenta que hace vulnerables a quienes participan de ella. La conyugalidad se convierte en un elemento central que permite generar procesos de resocialización para integrarse a la vida legal, en el que la mujer juega un papel central en la medida en que logra ejercer su rol como cuidadora, protectora y pacificadora de ese otro.

\section{Conclusión}

Si bien las cifras oficiales muestran que el mundo de la violencia armada sigue ampliamente liderado y conformado por sujetos masculinos, no se puede negar que la participación de las mujeres dentro de este cada vez comienza a ser mayor, dinámica que resulta interesante de comprender para dar cuenta de la caída de estos mitos pero, a su vez, para evidenciar que estas participaciones no necesariamente significan la ruptura de relaciones patriarcales fuertemente definidas en el mundo social y que la mayoría de veces se reproducen enfáticamente en estos espacios de violencia.

Como lo hemos presentado en este documento, las experiencias de estas jóvenes mujeres que han tenido vínculos con actores armados en la ciudad, nos señalan tres roles que experimentan en dichas relaciones: como parejas dentro del mundo ilegal, como cuerpos de intercambio y sujetos de repulsión y como mujeres alentadoras de la redención de los sujetos armados. Estas tres posiciones donde han sido puestas y donde ellas se asumen, señalan una fuerte reproducción de los estereotipos que son acogidos para definirse a sí mismas y posicionarse en relación con el mundo social que las rodea. 
Violencia armada y género: análisis de la relación a partir de los relatos de vida de jóvenes mujeres de la ciudad de Cúcuta...

\section{Referencias}

Blair, E. y Londoño, L. (2003). Experiencias de guerra desde la voz de las mujeres. Revista Nómadas, 19, 106-115.

Cañizáres, W. y Niño, E. (2017). Una mirada local al crimen organizado en la frontera colombovenezolana. Cúcuta, Colombia: Fundación Progresar.

Castelletti, C. (2016). Las "narcas": estereotipos de género en los roles y funciones de las mujeres que integran una asociación ilícita para el tráfico de drogas. En M. Ledesma. (Coord.), Género y Justicia. Estudios e investigaciones en el Perú e Iberoamérica (pp. 299-328). Lima, Perú: Centro de Estudios Constitucionales, Tribunal de Justicia de Perú.

Castro, G. (2011). Experiencias de violencia política vividas por mujeres del centro y norte del Valle del Cauca, Colombia. Cali, Colombia: Universidad del Valle.

Chamorro, L. (2012). Los cautiverios de niñas y jóvenes excombatientes de grupos armados colombianos. Trabajo Social, 14, 127-144.

Comisión Interamericana de Mujeres. (2014). Mujeres y drogas en las Américas. Un diagnóstico de política en construcción. Recuperado de http://www.oas.org/en/cim/docs/ womendrugsamericas-es.pdf

Domínguez, M. (2003). La Playboy: la participación de hombres y mujeres en una pandilla juvenil de Siloé, Cali. Revista Sociedad y Economía, 5, 83-107.

González, J. D., González, A. y Moscoso, M. (2012). Mujeres delincuentes en Colombia: una aproximación a su caracterización y visibilización. [Inédito].

Ibarra, M. (2009). Mujeres e insurrección en Colombia, reconfiguración de la identidad femenina en la guerrilla. Santiago de Cali, Colombia: Pontificia Universidad Javeriana.

INDEPAZ. (2017). El complejo paramilitar se transforma. Recuperado de http://www.indepaz. org.co/wp-content/uploads/2017/03/03.17-EL-COMPLEJO- PARAMILITAR-1.pdf

Instituto Nacional de Medicina Legal. (2017). Forensis. Datos para la vida. Recuperado de: http: / /www.medicinalegal.gov.co/documents/20143/49526/Forensis+2016.+Datos + para+la+vida.pdf

Lagarde, M. (2005). Los cautiverios de las mujeres: madresposas, monjas, putas, presas y locas. Ciudad de México, México: UNAM.

Lara, P. (2000). Las mujeres en la guerra. Bogotá, Colombia: Planeta.

Muñoz, A. (2003). La doncella guerrera encarnada en Juana de Arco. La subjetivación femenina de un tópico ¿androcéntrico? En M. Nash. y S. Tavera. (Eds.), Las mujeres y las guerras. 
El papel de las mujeres en las guerras de la edad antigua a la contemporánea (pp. 110-131). Barcelona, España: Icaria.

Niño, N. (2016). Género y juventudes. Chiapas, México: Colegio de la Frontera Sur.

Niño, N. (2017). Las tramas de la violencia: construcción de subjetividad política en niños, niñas y jóvenes en contextos de violencia armada (Tesis de doctorado). FLACSO, Ciudad de México, México.

Ovalle, L. y Giacomello, C. (2008). La mujer y el 'narcomundo': imágenes tradicionales y alternativas. Arenas. Revista sinaloense de Ciencias Sociales, 17, 32-45.

Pécaut, D. (2001). Guerra contra la sociedad. Bogotá, Colombia: Editorial Planeta.

Rayas, L. (2009). Armadas. Un análisis de género desde el cuerpo de las mujeres combatientes. Ciudad de México, México: El Colegio de México.

Segato, R. (2014). Las nuevas formas de la guerra y el cuerpo de las mujeres. Puebla, México: Pez en el árbol.

Silvera, S. (2015). Grupos postdesmovilización en la frontera con Venezuela. Recuperado de http: / / www.arcoiris.com.co/wp-content/uploads/2015/10/Neoparamilitares-en-la-fronteracon-Venezuela-versi\%C3\%B3n-larga.docx-2-1.pdf

Valenzuela, J. (2010). Jefe de jefes. Corridos y narcocultura en México. Tijuana, México: COLEF. 